\title{
The Decentralization Turns in Design: An Exploration Through the Maker Movement
}

\begin{abstract}
This article recollects paradigms and turns in the Design research and practice integrating several contributions and elaborates a new proposal arguing that the current changes are not about a single shift from one center to another, but rather the decentralization and distribution to several new centers becoming thus a system of Decentralization turns in Design. This system is structured with eight turns: Do It Yourself approaches to Design, Open Design, Network Science approach to Design, Distributed Manufacturing, Design and Locality, Design and Decolonization, Posthuman Design, Design, Data, Software and Artificial Intelligence. These eight turns are transforming design practice and research along eight dimensions (meta, who, what, where, how, tools, process, scale), here explored through the context of the Maker Movement.
\end{abstract}

\section{Keywords}

Decentralization, Design Turns, Maker Movement, Posthuman

\section{Introduction}

The understanding of the evolution, revolutions, general dynamics and changes in the history of science is a crucially strategic endeavor. In this sense, one of the most influential contribution was elaborated by Kuhn [1], who theorized that science evolves through revolutions based on paradigm shifts that move the focus from one center to a new one, transforming how science is done and understood and generating new eras in science. Besides epoch-making paradigms science presents also turns, which are smaller-scale changes that take place more as parallel and overlapping [2, 3] and can be considered a product of their own time. At different levels, decentralization is a crucial element of the history of science. This paper aims to contribute to this discussion regarding Design, by tracing a first exploratory timeline of paradigms and turns in the design research and practice, and by identifying a further turn that takes place now. Therefore, it proposes the extension of these turns not by showing the displacement from one center to a new one, but by distributing the center to several new centers in what is can be then described as a set of Decentralization turns in Design. Moreover, the identification of such new turns is based on eight turns bringing decentralization to design along eight dimensions. Although these dimensions have several different roots and also applications, this paper describes them in the specific 
context of the Maker Movement [4, 5]; as one of the more recent evolution of the Design practice and with extended implications, it offers examples for all the identified turns. Based on this context, this paper aims to answer the following research question: What are the decentralizations that have been emerging in the design research and practice, and how they can possibly characterize new turns in Design? In order to answer that, this research explores with a literature review the previous turns in design, and elaborates a coherent system of turns in Design and in the Maker Movement.

\section{A Review of Paradigms and Turns in Design}

The identification of paradigms and turns in Design might have less tradition than in other disciplines. While some authors provide an overview of timelines of different paradigms and turns, others develop single turns that show their underlying research and practice, exploring the role of designers and users, and also of the methods and theories applied. Such paradigms and turns present changes in design practice, roles, processes and concepts, and we focused specifically on the proposals that focus on agency by shifting who design and how.

One of the main contributions in the identification of paradigms in design can be found in the four economic paradigms identified and described by Gardien,

Djajadiningrat, Hummels, and Brombacher: the Industrial, Experience, Knowledge and Transformation economies [6]. This framework is mainly focused on companies and how they can innovate in order to keep up with paradigm changes. In the Industrial Economy, mass production and a modernist machine aesthetic are based on efficient design activities that are objectively measurable and follow a linear rational problem-solving process. In the Experience Economy, differentiation is created through branding as a way to enable users to belong to subcultures with a plurality of diverse styles. The work of designers here extends beyond object-centered thinking to the total user experience and follows two approaches to processes: reflective practice and user-centered design. In the Knowledge Economy, an overflow of brands and the emergence of the remix culture of online communities enable users to reach self-actualization through a DIY remix of subcultures into individual custom subculture: belonging happens through a personal remix of one own's identity. Companies create value through an open innovation process based on communities of users with an open design, co-created and participatory approach. Now the works of designers is in orchestrating open innovation through algorithmic thinking, data visualization and creative coding. The Transformation Economy is the latest and still emerging paradigm, where concerns about pollution, global warming and wealth disparity push the work of designers towards understanding societal values and foster reciprocal value creation with a systemic approach to local solutions through platforms that enable plural and radical approaches.

In terms of turns, although design researchers have already identified turns in design in the past [3, 7], there is not a consensus in their definition, identification, and meaning of the word "turn" in the design field. We consider a starting point for the study of turns in design the paper of Marttila and Botero [3], who identified four turns related to "co" in co-design: Usability, Sociability, Designability, and Openness. For them turns are more parallel, overlapping, mixed and connected than paradigm shifts. In other words, a turn is a device for communicating the identified changes. The Usability turn can be considered the first turn in Co-design, and it has a clear emphasis on the user and the use situation. It provides an impulse to the development of the concept of Human Centered Design (HCD) and constitutes the basis of research and literature in Human-Computer Interaction $(\mathrm{HCl})$ [8]. Here, the user can be described as a consumer, and the primary purpose of design is to make them consume the final result of the design process. The second turn is described as the Sociability turn and it is characterized by the attention to the relationship between peoples' practices and to facilitating stakeholders' contributions $[3,9,10]$. Moreover, the Sociability turn defines design collaboration as enacted through organized events (e.g. workshops) initiated by experts, in which users are considered stakeholders who are not merely passive consumers, instead they become more active and form partnerships [11], supporting the development of practices like co-design and participatory design.

Therefore, Design acquires a broader notion, involving activities that support people's wishes to become 
active participants and contributors in personally meaningful activities [12], which characterize and develop the Designability turn. Moreover, users need to be empowered "to act as designers" [13], which is related to the concept of Meta-Design. In the MetaDesign approach, users are seen as potential designers by extending, improving and appropriating design, while designers are the ones in charge to create social and technical infrastructures to enable new forms of collaboration. This differs from the Openness turn, that is solely based on the adoption of digital technologies and the rise of the Open Source Movement, enabling new forms of organization and distribution of resources through sharing and collaboration [14]. New spaces and conditions for practice can be developed regarding the openness of projects, the rise of new practices and the sharing of knowledge and information, enabling new forms of collaborative interactions. Moreover, it allows end users to share projects and access to digital fabrication technologies to prototype and manufacture products locally [15-17]. The openness of design changes and challenges some of the current paradigms of design practice, such as: authorship, and the idea that every design project should end with a commodified and final outcome. Two main strands can be identified in the practice and literature on Open Design: a predominant one focusing on design artifacts in which the emphasis is on the openness of publicly available designs (e.g., blueprints as documents), and a broader approach to open-ended design activities and practices.

Other authors propose single turns instead of a timeline of turns, such as the Semantic, Openness and Peerto-Peer, Systemic and Posthuman turns. Krippendorf [7] describes the Semantic turn in design as a shift in designing artifacts that moves the center from how artifacts ought to function to what they mean to those affected by them: the design of an artifact entail more than just its form and aesthetic, it is also connected to users' beliefs, values, needs, and emotions. The Systemic turn is distinguished from others in terms of scale, social complexity, and integration. By integrating systems thinking and its methods, this turn extends Human-Centered Design towards complex and multistakeholder service systems [18], an aspect that is also related to the idea of layers and interdependence of different turns. In the Openness and Peer-to-Peer turn Menichinelli adds the Peer-to-Peer (P2P) and Meta-
Design approaches to the Openness turn, considering how design can adopt open source and P2P practices and how it could use its tools, practice and resources for implementing open source and P2P practices [19]. Within the context of this research, this turn becomes relevant since it openly proposes decentralization as both an explicit core value and objective. The metadesign approaches detailed in this turn explicitly use design tools and approaches not just for operating within decentralized systems, but also for creating them. The importance of decentralization is here an inheritance of the origin of these phenomena from Internet-based organizations and its historical decentralized architecture elaborated by Baran [20]. In the Posthuman turn described by Forlano, design is a way to resist to binary categories and integrate humans and the non-humans as social constructions, which is connected to the development and use of new technologies and a new understanding of agency [21]. Posthumanism criticizes the anthropocentrism, extending the limits of the human also to the ethical, social, and political sphere in which humans operates. The agency of artifacts distances the centrality of humans in design research and practice, moving towards a more complex system of interactions between human and non-human actors. Moreover, this comprises how socio-technical systems can be socially constructed, but also how they can shape society. Therefore, not only it discusses the interactions between human and non-humans, it is also a way to break the notion of subjectivity (subjectivities and identities constructed through race, class, gender, sexuality, and ability) in Design.

\section{The Decentralization Turns in Design and the Maker Movement}

Several turns in Design have emerged in the last decades, sometimes overlapping and sometimes disconnected among them. Some of these turns are now increasingly integrated because of the recent technological, social and economic changes, bringing an additional displacement to the ones documented in the previous section. To better understand the possible changes and opportunities that can be related to decentralization, as an integrated and transitory set of turns, we analyze how this unfolds in the relation between the Maker Movement and the Design practice 
and research. In this context, the Maker Movement is not seen as the only cause of this new turn, but more as one of the causes and one of the effects of such turn at the same time, both an outcome and a catalyst of these changes, and the context that inspired this research and the reflections.

Through this analysis, we aim to identify what are the clear forces towards the decentralization in design, divided by eight turns and eight dimensions in which the effects decentralization takes place. We propose to call it as Decentralization turns, as it represents a clear force towards decentralization, multiplied by the integration of several turns and the extension of them. The deep changes behind this turn are aligned with the evolution of the design research and practice, which has recently moved its scope from single users to local and online communities, from isolated projects to complex system of solutions, and from harmful and misunderstood impact on the environment to a long-term, inseparable, aware and unavoidable blending with it.

We argue then that this is not just a Maker Movement turn but a thorough, complex and articulated phenomenon. Therefore, the Maker Movement and its integration with Design research and practice can be where all the recent decentralization processes are meeting, showing that there are wider and more profound implications than just the use of 3D printing technologies and informal education and design. Within this context, the system of Decentralization turns in Design can be identified in eight distinct categories: 1) Do It Yourself (DIY) approaches to Design, 2) Open Design, 3) Network Science approach to Design, 4) Distributed Manufacturing, 5) Design and Locality, 6) Design and Decolonization, 7) Posthuman Design and 8) Design, Data, Software and Artificial Intelligence (Al). Depending on what is decentralized in the design research and practice, these categories can be analyzed along eight dimensions: a) meta (shifting elements to the meta level), b) who (changing whom of the different actors have agency), c) what (changing what is designed), d) where (displacing the location of design activities), e) how (transforming methods and approaches), f) tools (changing the tools adopted), g) process (transforming processes), h) scale (changing scale of the design initiatives). This structure, displayed in Table 1, is a first approach at assessing the level of decentralization in design projects and activities, depending on how many turns and dimensions are decentralized. Within such Design Decentralization Score (DDS), each turn is equivalent to $12.5 \%$ of a full decentralization; if we consider both turns and dimensions, each cell in the table represents instead of $1.5625 \%$ of a complete decentralization.

As a starting point, the turn of DIY approaches to Design (1) is a foundational point that challenges who is the designer; the boundaries between amateur and professional designers are increasingly blurred [22-24]. Following the pioneering example of Enzo Mari [25] makers but and designers embrace and promote this turn for the development of projects [26]. Moreover, the DIY approach has been applied by both designers and makers to the production of new resources and materials [27]. This turn also brings changes to where design is done (e.g. at home or in a makerspace), and what tools can be used in a nonprofessional environment, often pointing out how design practice can be part of the informal economy [28].

The turn of Open Design (2) is an extension of the first one, as developing projects independently is often based on the sharing of projects, tools and documentation, including the Openness, Openness and P2P turns. After the pioneering work of individual designers like Ronen Kadushin [29] and of experimental digital platforms like Thinkcycle [30], now Open Design is a

Table 1. The Decentralization turns in Design: turns and dimensions

\begin{tabular}{|c|c|c|c|c|c|c|c|c|}
\hline & meta & who & what & where & how & tools & process & scale \\
\hline DIY Design & & & & & & & & \\
\hline Open Design & & & & & & & & \\
\hline Network & & & & & & & & \\
\hline Distributed & & & & & & & & \\
\hline Manufacturing & & & & & & & & \\
\hline Locality & & & & & & & & \\
\hline Decolonization & & & & & & & & \\
\hline Posthuman & & & & & & & & \\
\hline Data, Software, Al & & & & & & & & \\
\hline
\end{tabular}


common practice thanks to makers and well established platforms like Thingiverse [31].

The often collaborative and collective dimension of Open Design brings the category of a 3) Network Science approach to Design, mainly for research purposes at the moment, with the aim of uncovering how the social interactions influence design processes and projects, for example platforms such as Github [32] or Thingiverse [31]. Network analysis is typically implemented in order to understand 1) structural dependencies within products and systems, 2) communication, cooperation and competition in design processes, 3) social, economic, institutional environment of design processes [33].

The often distributed nature of Open Design initiatives brings the increasing relevance of a 4) Distributed Manufacturing ecosystem of Fab Labs, Makerspaces, craft workshop, micro-factories and other digitally connected places where digital fabrication and traditional processes enable the manufacturing of open projects $[4,5,15,16]$.

Distributed Manufacturing systems are not only a digital layer that erases the local differences, but enhances them, as several examples of maker initiatives that re-evaluate local traditions and craft show [34]. Several examples of projects designed with and for digital fabrication have been collected [35], and an interesting case is Circular Knitic by the artists Varvara Guljajeva and Mar Canet, an open source digital knitting machine [36].

In this category, the Maker Movement further promotes the work on 5) Design and Locality of previous design initiatives $[37,38]$. This turn focuses not only on users and markets for developing products and services, but on the local conditions, communities, economies and cultures and work at improving them at the same time. An example in this case is the Fab Loom [34, 39], a traditional Peruvian loom by Walter Gonzales Arnao redesigned and fabricated with digital technologies which enables collaborative processes in its development, usage and dissemination.

The role of locality in design brings the importance of Decolonization (6) in its approaches, which further extends the previous turn by strongly focusing on the empowerment of local communities through projects that can develop a design approach following the local culture [40]. This turn is emerging in several maker initiatives [41] but it is however less explored, and further research should clarify if and when the Maker Movement is really advancing decolonization, or instead proposing a new form of technological and cultural colonization, or both at the same time for the moment. An example of this can be found in the many initiatives of indigenous communities for building drones for community mapping activities that aim at reclaiming ownership of their territories against government and companies [42]. Drones are an iconic project in the Maker Movement, and not only makers and designers are using them, but also designing, fabricating and releasing them openly as Noumena did with the NERO project [35], who then also deployed it in Costa Rica for the 3D scanning of pineapple plantations in collaboration with local makers [43].

Further along this direction, the Posthuman design turn (7) supports emergent critical race, gender and decolonial theories. Therefore, Posthuman in design changes the perspective of what is agency, who has agency, and how it can shape interactions. In the Decentralization Turn, posthumanism shifts the agency from the human who was placed in the center of the design actions, and takes into the consideration the locality and different agents - like technology, the environment and other entities as also capable of shaping interactions. In the Maker Movement, this approach often takes place with work on synthetic biology projects that enables living organisms to produce materials and artifacts; makers have already started coupling this with open source 3D printers $[44,45]$.The decentralization of the role of human actors towards non-human ones in terms of agency is also connected to the increasing connections among 8) Design, Data, Software and Al, where software is not just a tool any longer but a creative actor in the generation of projects [46, 47]. While Generative Design approaches have been around for decades, with the digital fabrication technologies and the attitude provided by the Maker Movement designers like MHOX are increasingly treating software as a design material that acts semi-autonomously [48]. 


\section{Conclusion}

Based on a critical reflection on the literature, this research explores different turns in the Design research and practice. We propose not a new turn, but a set of turns called the Decentralization turns which represent a clear force towards decentralization along the integration and extension of the previous turns. As an initial step towards its development and better understanding, we propose a set of decentralization forces, divided by eight turns and eight dimensions. We use the Maker Movement as the starting point, context and example of the preliminary analysis of these forces. This proposal aims at contributing more insights, approaches and practices to the Design research and practice, highlighting emerging possibilities and their architecture. However, further analysis is necessary in order to verify and suggest new modes of operation regarding distributed, hyperconnected, and complex intelligent ecosystems. The next steps can be directed towards a) the exploration of their impacts on the design process, user experience, social consequences, and the role of designers, b) the validation of the proposed score through the developing a composite index based on multiple data sources and capable of integrating the eight turns and dimensions [49] in order to measure the level of decentralization. Finally, as consequence of the lack of consensus on the concept of turns and paradigms in design, there is not a strong theoretical background: a more rigorous analysis of turns and paradigms in design research and practice is necessary.

\section{References}

1. Kuhn, T.S.: The structure of scientific revolutions. University of Chicago Press, Chicago (1962).

2. Merriam-Webster: Definition of TURN, https://www. merriam-webster.com/dictionary/turn, (2019).

3. Marttila, S., Botero, A.: The "Openness Turn" in Co-Design. From Usability, Sociability and Designability Towards Openness. In: Co-create 2013, the boundary-crossing conference on Co-design in Innovation. pp. 99-110. Aalto University, Espoo, Finland (2013).

4. Anderson, C.: Makers: The New Industrial Revolution. Crown Business, New York (2012).

5. Gershenfeld, N.: FAB: The Coming Revolution on Your Desktop--From Personal Computers to Personal
Fabrication. Basic Books, New York (2005).

6. Gardien, P., Djajadiningrat, T., Hummels, C., Brombacher, A.: Changing your hammer: The implications of paradigmatic innovation for design practice. Int. J. Des. 8, 119-139 (2014).

7. Krippendorff, K.: The semantic turn: a new foundation for design. CRC/Taylor \& Francis, Boca Raton (2006).

8. Grudin, J.: The computer reaches out: the historical continuity of interface design. In: Proceedings of the SIGCHI conference on Human factors in computing systems. pp. 261-268. ACM (1990).

9. Ehn, P.: Participation in design things. In: Proceedings of the Tenth Anniversary Conference on Participatory Design 2008. pp. 92-101. Indiana University, Indianapolis, IN, USA (2008).

10. Redström, J.: RE:Definitions of use. Des. Stud. 29, 410-423 (2008). https://doi.org/10.1016/j.destud.2008.05.001.

11. Sanders, E.B.-N., Stappers, P.J.: Co-creation and the new landscapes of design. CoDesign Int. J. CoCreation Des. Arts. 4, 5 (2008). https://doi.org/10.1080/15710880701875068.

12. Fischer, G., Scharff, E.: Meta-design: design for designers. In: Proceedings of the 3 rd conference on Designing interactive systems: processes, practices, methods, and techniques. pp. 396-405 (2000).

13. Fischer, G., Giaccardi, E.: Meta-design: A Framework for the Future of End-User Development. In: Lieberman, $\mathrm{H}$., Paternò, F., and Wulf, V. (eds.) End User Development. pp. 427-457. Springer Netherlands, Dordrecht (2006).

14. Goetz, T.: Open Source Everywhere, http://www.wired.com/ wired/archive/11.11/opensource.html, (2003).

15. Abel, B., Evers, L., Klaassen, R., Troxler, P. eds: Open Design Now: why design cannot remain exclusive. BIS Publishers, Amsterdam (2011).

16. Bauwens, M.: The Emergence of Open Design and Open Manufacturing, http://www.we-magazine.net/we-volume-02/, (2009).

17. Bakırlıoğlu, Y., Kohtala, C.: Framing Open Design through Theoretical Concepts and Practical Applications: A Systematic Literature Review. Human-Computer Interact. 0, 1-45 (2019). https://doi.org/10.1080/07370024.2019.157422 5.

18. Jones, P.H.: Systemic Design Principles for Complex Social Systems. In: Metcalf, G.S. (ed.) Social Systems and Design. pp. 91-128. Springer Japan, Tokyo (2014). https://doi. org/10.1007/978-4-431-54478-4_4.

19. Menichinelli, M.: A Framework for Understanding the Possible Intersections of Design with Open, P2P, Diffuse, Distributed and Decentralized Systems. Disegno - J. Des. Cult. III, 44-71 (2016). https://doi.org/10.21096/ 
disegno_2016_1-2mm.

20. Baran, P.: On distributed communications. RAND

Corporation, Santa Monica, CA. (1964).

21. Forlano, L.: Posthumanism and Design. She Ji J. Des. Econ. Innov. 3, 16-29 (2017). https://doi.org/10.1016/j. sheji.2017.08.001.

22. Atkinson, P.: Boundaries? What Boundaries? The Crisis of Design in a Post-Professional Era. Des. J. 13, 137-155 (2010). https://doi.org/10.2752/175470710×12735884220817.

23. Gerritzen, M., Lovink, G.: Everyone is a Designer In the Age of Social Media. BIS Publishers, Amsterdam (2010).

24. Manzini, E.: Design, When Everybody Designs: An Introduction to Design for Social Innovation. The MIT Press, Cambridge, Massachusetts (2015).

25. Mari, E.: Autoprogettazione? Corraini, Mantova (2002).

26. Recession Design: Design fai da te 2.0. Nuove idee contro la crisi. Rizzoli, Milano (2013).

27. Rognoli, V., Bianchini, M., Maffei, S., Karana, E.: DIY materials. Mater. Des. 86, 692-702 (2015). https://doi.org/10.1016/j. matdes.2015.07.020.

28. Paton, E., Lazazzera, M.: Inside Italy's Shadow Economy. N. Y. Times. (2018).

29. Kadushin, R.: Open design manifesto, http://www.ronenkadushin.com/files/4613/4530/1263/Open_Design_ Manifesto-Ronen_Kadushin_.pdf, (2010).

30. Sawhney, N., Griffith, S., Maguire, Y., Prestero, T.: ThinkCycle: sharing distributed design knowledge for open collaborative design. Int'l J Technol. Adv. Knowl. Learn. TechKnowLogia. 4, 49-53 (2002).

31. Flath, C.M., Friesike, S., Wirth, M., Thiesse, F.: Copy, transform, combine: exploring the remix as a form of innovation. J. Inf. Technol. 32, 306-325 (2017). https://doi. org/10.1057/s41265-017-0043-9.

32. Menichinelli, M.: A data-driven approach for understanding Open Design. Mapping social interactions in collaborative processes on GitHub. Des. J. 20, S3643-S3658 (2017). https://doi.org/10.1080/14606925.2017.1352869.

33. Chen, W., Heydari, B., Maier, A.M., Panchal, J.H.: Networkbased Modeling and Analysis in Design. Des. Sci. 4, (2018). https://doi.org/10.1017/dsj.2018.8.

34. Gonzales Arneo, W.: El impacto tecnológico en la artesanía peruana. Universidad Nacional de Ingeniería, Facultad de Arquitectura, Urbanismo y Artes, Instituto de Investigación INIFAUA, Lima (2017).

35. Menichinelli, M.: Le galerie Fab. In: Menichinelli, M. (ed.) Fab lab : la révolution est en marche. Editions Pyramyd, Paris (2015).

36. Guljajeva, V., Canet, M.: Circular Knitic - Varvara \& Mar, http://var-mar.info/circular-knitic/.

37. Verwijnen, J., Karkku, H.: Spark! - design and locality. University of Art and Design Helsinki, Helsinki (2004).

38. Fagnoni, R., Gambaro, P., Vannicola, C.: Medesign: forme del Mediterraneo. Alinea, Firenze (2004).

39. Medialab-Prado: Fab Loom, https://vimeo.com/153486819.

40. Escobar, A.: Designs for the Pluriverse: Radical Interdependence, Autonomy, and the Making of Worlds. Duke University Press Books, Durham (2018).

41. Garber, E., Hochtritt, L., Sharma, M. eds: Makers, Crafters, Educators: Working for Cultural Change. Routledge, New York, NY (2018).

42. Clayton, A.: Cartographers Without Borders, https:// logicmag.io/03-cartographers-without-borders/, (2018).

43. Noumena: NERO - COSTA RICA, https://vimeo. com/175519889.

44. Myers, W., Antonelli, P.: Bio Design: Nature + Science + Creativity. The Museum of Modern Art, New York, New York (2012).

45. Alasdair, A.: 3D Printing Using Genetically Modified Bacteria and Orange Juice, http://makezine.com/2014/11/15/3dprinting-using-genetically-modified-bacteria-and-orangejuicel.

46. Shiffman, D., Fry, S., Marsh, Z.: The nature of code. (2012).

47. Reas, C., McWilliams, C.: Form+Code in Design, Art, and Architecture. Princeton Architectural Press (2010).

48. Dezeen: Using computer algorithms in design is like "sculpting with a new material," https://www.youtube.com/ watch? $v=y 3 d Q X e N K U Y M \&$ feature=youtu.be.

49. OECD, JRC eds: Handbook on constructing composite indicators: methodology and user guide. OECD, Paris (2008). 